\title{
Isolate Specificity and Polygenic Inheritance of Resistance in Barley to the Heterologous Rust Pathogen Puccinia graminis f. sp. avenae
}

\author{
P. M. Dracatos, M. Nansamba, A. Berlin, R. F. Park, and R. E. Niks
}

First and fourth authors: The University of Sydney, Plant Breeding Institute, Cobbitty, Private Bag 4011, Narellan, NSW, 2567, Australia; second and fifith authors: Wageningen University and Research Center (WUR), Laboratory of Plant Breeding, 6700 AJ Wageningen, The Netherlands; and third author: Department of Forest Mycology and Plant Pathology, Swedish University of Agricultural Sciences, Box 7026, SE-750 07 Uppsala, Sweden.

Accepted for publication 15 April 2016.

\begin{abstract}
Dracatos, P. M., Nansamba, M., Berlin, A., Park, R. F., and Niks, R. E. 2016. Isolate specificity and polygenic inheritance of resistance in barley to the heterologous rust pathogen Puccinia graminis f. sp. avenae. Phytopathology 106:1029-1037.

Barley is a near-nonhost to numerous heterologous (nonadapted) rust pathogens because a small proportion of genotypes are somewhat susceptible. We assessed 66 barley accessions and three mapping populations (Vada $\times$ SusPtrit, Cebada Capa $\times$ SusPtrit, and SusPtrit $\times$ Golden Promise) for response to three Swedish oat stem rust (Puccinia graminis $\mathrm{f}$. sp. avenae) fungal isolates and determined that barley is a near-nonhost to $P$. graminis f. sp. avenae and that resistance was polygenically inherited. The parental

genotypes Vada and Golden Promise were immune to all three isolates, whereas Cebada Capa was immune to two isolates and moderately resistant to the third. Phenotypic data from the Vada $\times$ SusPtrit mapping population and the barley accessions tested also demonstrated isolate-specific resistance. In particular, the SusPtrit parent and several other accessions allowed sporulation by isolate Ingeberga but were resistant to isolate Evertsholm. Nine chromosomal regions carried quantitative trait loci (QTL) (Rpgaq1 to Rpgaq9) of varying effect, most of which colocated to previously identified QTL for resistance to other heterologous rust pathogens. Rpgaq1 on chromosome $1 \mathrm{H}$ (Vada and Golden Promise) was effective toward all isolates tested. Microscopic examination indicated that resistance was prehaustorial in Vada whereas, in SusPtrit, both pre- and posthaustorial mechanisms play a role.
\end{abstract}

Stem rust, caused by Puccinia graminis, attacks many grasses, including the economically important cereals (wheat, barley, and oats) on which severe levels of infection can cause total crop failure. $P$. graminis comprises subspecies and formae speciales, based primarily on infection structure morphology and host range (Leonard and Szabo 2005; Niks 1986). Oat stem rust, caused by the forma specialis $P$. graminis f. sp. avenae, is a major constraint to oat (Avena sativa $\mathrm{L}$.) production in Europe and Australia. For instance, Mellqvist and Waern (2010) reported yield losses of up to $30 \%$ in untreated Swedish oat fields. Sexual recombination on the alternate barberry (Berberis vulgaris L.) host facilitates meiotic recombination, often resulting in new virulence on previously resistant oat cultivars (Berlin et al. 2013; McDonald and Linde 2002). Sexual reproduction in Swedish $P$. graminis f. sp. avenae populations has been reported frequently, especially since the repeal of legislation to eradicate barberry (Berberis spp.) bushes in the agricultural landscape (Berlin et al. 2013). Nonetheless, in the absence of barberry, the pathogen survives and reproduces on wild oats, volunteer oat plants, and certain grass species (Burdon et al. 1992). Changes in the pathogen populations in areas where alternate hosts are absent are thought to be caused by step-wise mutations, genetic drift, and the immigration of exotic genotypes. The ability of $P$. graminis f. sp. avenae to develop virulence for resistance genes in commercial oat cultivars is of particular concern to oat breeders, who now seek more durable sources of resistance.

Disease resistance shown by all genotypes of a particular plant species to a specific pathogen species is known as nonhost resistance.

Corresponding author: P. M. Dracatos; E-mail address: peter.dracatos@sydney.edu.au

P. M. Dracatos and M. Nansamba contributed equally as first authors of this manuscript.

http://dx.doi.org/10.1094/PHYTO-10-15-0264-R

(C) 2016 The American Phytopathological Society
The concept of nonhost resistance has gained significant research interest from an evolutionary point of view. Due to its presumed durability and lack of specificity toward variants of a pathogen, a better understanding of nonhost resistance may lead to more effective breeding and control options. The differentiation between host and nonhost status is sometimes unclear (Heath 1985; Niks 1987). Within a presumed nonhost plant species, there are occasionally a few genotypes that are moderately susceptible to a normally heterologous (nonadapted) rust pathogen. Such occasional receptivity (Niks 1987) is also referred to as near-nonhost (Atienza et al. 2004) or marginal host status (Jafary et al. 2006). Barley (Hordeum vulgare L.) has been reported to be a near-nonhost to several heterologous rust pathogens (Atienza et al. 2004; Mains 1933; Martens et al. 1977; Niks 1987; Niks et al. 1996). Due to the availability of useful genetic resources (Atienza et al. 2004; Jafary et al. 2006, 2008) and recent genomic advancements, the barley-Puccinia spp. interaction represents one of the most attractive model systems to study the genetics underlying host and (near-) nonhost status in crop species.

Atienza et al. (2004) developed an experimental barley line, SusPtrit (susceptible to $P$. triticina), by accumulating susceptibility alleles from four unrelated barley accessions that were somewhat susceptible at the seedling stage to the heterologous wheat leaf rust pathogen ( $P$. triticina). SusPtrit at the seedling stage was not only as susceptible to $P$. triticina as a regular wheat seedling but, also, more or less susceptible to several other heterologous rust pathogen species (Atienza et al. 2004). Subsequent genetic studies in different mapping populations based on the use of SusPtrit as a parent indicated that resistance to heterologous rust pathogens in immune barley cultivars such as Vada, Cebada Capa, and Golden Promise is polygenically inherited with the rare involvement of a major resistance $(R)$ gene (Jafary et al. 2006, 2008; Yeo et al. 2014). The regular nonhost immunity of Vada, Cebada Capa, and Golden Promise to heterologous rust fungi is due mostly to different genes, and there were overlapping specificities when the same quantitative trait loci (QTL) 
in a cultivar might confer resistance to more than one heterologous rust pathogen (Jafary et al. 2006, 2008; Yeo et al. 2014).

Previous studies indicated that $P$. graminis f. sp. avenae can infect a few barley accessions at the seedling stage, suggesting that it may be a near-nonhost to $P$. graminis $\mathrm{f}$. sp. avenae. A barley selection (73-G1) that was somewhat susceptible to $P$. graminis f. sp. avenae demonstrated that resistance was heritable and differed from the $\mathrm{T}$ gene (now designated Rpg1) conferring resistance to the wheat stem rust pathogen (P. graminis f. sp. tritici) (Martens et al. 1983). A recent study demonstrated the presence of prehaustorial resistance in a doubled haploid (DH) population based on the Australian barley cultivars Yerong and Franklin in response to three different $P$. graminis f. sp. avenae pathotypes from Australia and Canada (Dracatos et al. 2014). The QTL identified in that population (Rpgal to Rpga5) were located on chromosomes $1 \mathrm{HS}, 5 \mathrm{HL}$, and 7HS, mainly at locations not previously reported in other barley mapping populations to contain genes for resistance to heterologous rusts (Jafary et al. 2006, 2008; Yeo et al. 2014). Furthermore, no $P$. graminis f. sp. avenae isolate specificity was identified in the QTL mapping experiments (Dracatos et al. 2014). Previous studies have determined that, in some cases, resistance to P. graminis f. sp. avenae in barley is simply inherited (Dracatos et al. 2015; Martens et al. 1983). Dracatos et al. (2015) intercrossed barley cv. Q21861 (Rpg5-immune to P. graminis f. sp. avenae) and the experimental line 73-G1 (rpg5) and determined that the Rpg5 locus on chromosome 5HL conferred resistance to both Australian pathotypes of $P$. graminis $\mathrm{f}$. sp. avenae tested. This suggests that Rpg 5 confers resistance to multiple stem rust formae speciales, including $P$. graminis f. sp. avenae (Dracatos et al. 2015), P. graminis f. sp. tritici (Jin et al. 1994), and the rye stem rust pathogen (P. graminis f. sp. secalis) (Sun et al. 1996). The current study was aimed at determining the host status of barley to $P$. graminis $\mathrm{f}$. sp. avenae, the extent of isolate specificity of resistance QTL in barley, and the histology of resistance in Vada and SusPtrit barley compared with $P$. graminis f. sp. avenae infection on oats.

\section{MATERIALS AND METHODS}

Plant materials. A subset (66-due to lack of seed) of the previously described collection of 110 spring barley (Hordeum vulgare $\mathrm{L}$.) accessions from diverse geographic origins (Atienza et al. 2004) was used to assess the host status of barley to $P$. graminis f. sp. avenae. The collection comprised modern and old cultivars, landraces, and wild accessions for which passport data were available (Atienza et al. 2004). Two $\mathrm{F}_{9}$ recombinant inbred line (RIL) mapping populations (Vada $\times$ SusPtrit and Cebada Capa $\times$ SusPtrit and a DH population [SusPtrit $\times$ Golden Promise]) (Jafary et al. 2006, 2008; Yeo et al. 2014) were used for genetic studies of resistance to P. graminis f. sp. avenae. Genetic maps were available for these populations Vada $\times$ SusPtrit (152 RILs [Jafary et al. 2006]), Cebada Capa $\times$ SusPtrit (113 RILs [Jafary et al. 2008]) and SusPtrit $\times$ Golden Promise (122 DH lines [Yeo et al. 2014]).

Pathogen materials. Three field samples of $P$. graminis $\mathrm{f}$. sp. avenae (Pattala, Ingeberga, and Evertsholm) were collected from different locations in southern Sweden (Table 1). All field-derived $P$. graminis f. sp. avenae isolates could infect SusPtrit barley. Single pustule (SP) isolates were generated for the three field samples. To determine the virulence or avirulence of the three SP-derived $P$. graminis f. sp. avenae isolates, 19 oat differential testers were used for resistance genes including $P g 1, P g 2, P g 3, P g 4, P g 8, P g 9, P g 10, P g 13, P g 15$, $P g 16, P g 17, P g S a i a, P g A$, and the susceptible cultivar Swan. The Evertsholm SP isolate was developed from a random SP on Alfred oat. In initial studies, this SP isolate was unexpectedly not able to infect SusPtrit and only caused numerous pinpoint pale chlorotic flecks but no pustules. For Ingeberga and Pattala field isolates, we selected SP isolates from SPs that appeared on SusPtrit barley, hence assuring their pathogenicity on this barley accession. All SP isolates were subcultured onto adult susceptible Alfred oat plants for spore multiplication. Spore multiplication of SP isolates was performed in different greenhouse compartments, to prevent cross-contamination. Urediniospores of each SP isolate were collected, weighed, placed in a glass vial and were stored in a desiccator at room temperature. Surplus batches of spores were wrapped in aluminum foil, were placed in cryovials, and then, were stored in liquid nitrogen for future use.

Inoculation procedure. Nine days after sowing, the first leaf of each seedling was pinned horizontally to the soil with the adaxial side facing up. Seedlings for each line of the three mapping populations and the 66 diverse barley accessions were then inoculated with freshly collected urediospores in a settling tower. For every box containing 30 to 40 seedlings, $6 \mathrm{mg}$ of urediospores mixed with $48 \mathrm{mg}$ of lycopodium were applied to ensure uniform distribution of about 360 urediospores per square centimeter (Atienza et al. 2004). Following inoculation in a settling tower (Niks et al. 2011), the seedlings were incubated in a humidity chamber overnight at $100 \%$ relative humidity at approximately $20^{\circ} \mathrm{C}$ to permit urediniospore germination. On the next day, the plants were moved to a greenhouse compartment under both artificial and natural light. Rust testing was performed in two consecutive experiments on two to three seedlings per line per isolate. Only one isolate inoculation was performed per day, in order to prevent cross contamination of isolates. Oat differential lines were sown in five-inch pots at four lines (eight to 10 seeds per line) per pot and were inoculated using the settling tower and incubation conditions described above.

Phenotypic assessment of Puccinia graminis f. sp. avenae on barley. The three mapping populations and diverse barley accessions were assessed phenotypically with three (Ingeberga, Pattala, and Evertsholm) and two (Ingeberga and Evertsholm) Swedish SP P. graminis f. sp. avenae isolates, respectively. Barley seedlings (three per line) were grown in boxes $(37 \times 39 \mathrm{~cm})$ along with their parents and susceptible host (oat cv. Alfred). Twelve days after inoculation, the level of infection was quantified by two parameters: visible infection sites per leaf (VIS) (the number of both flecks and pustules per leaf) and infection frequency (IF) (the number of pustules per leaf) (Jafary et al. 2006). For VIS, flecks smaller than $0.5 \mathrm{~mm}$ in diameter (like the pinpoint flecks on SusPtrit with Evertsholm) were excluded from the counts. The level of infection of the panel of diverse barley accessions was scored according to a 0 to 5 scale, in which 0 indicates immunity or near-immunity (no visible sign of infection) and 5 (more than 500 pustules per leaf) (Atienza et al. 2004; Table 2). For QTL mapping, we first calculated the average VIS and IF for each line over the two or three seedlings per isolate. Secondly, VIS and IF ratings for each line were scaled by multiplication to obtain equal experiment averages. Correlation coefficients between replicates were also calculated, to establish the reproducibility of the phenotypic data.

TABLE 1. Characteristics of Swedish Puccinia graminis f. sp. avenae isolates used in this study

\begin{tabular}{|c|c|c|c|c|c|c|c|}
\hline \multirow[b]{2}{*}{ Isolate } & \multirow[b]{2}{*}{ Virulence on resistance genes ${ }^{z}$} & \multicolumn{2}{|c|}{ Location of collection } & \multicolumn{4}{|c|}{ Barley accession } \\
\hline & & Longitude & Latitude & Vada & Golden Promise & Cebada Capa & SusPtrit \\
\hline Evertsholm & $P g 1, P g 2, P g 3, P g 4, P g 9, P g A, P g 17$ & 58.49 & 16.26 & Immune & Immune & Immune & Resistant \\
\hline Pattala & $\operatorname{Pg} 1, \operatorname{Pg} 3, \operatorname{Pg} 8, \operatorname{Pg} 17$ & 59.05 & 16.43 & Immune & Immune & Resistant & Moderately resistant \\
\hline Ingeberga & Pg1, Pg3, Pg8, Pg9, Pg13, PgSaia, Pg17 & 59.65 & 16.69 & Immune & Immune & Resistant & Moderately susceptible \\
\hline
\end{tabular}

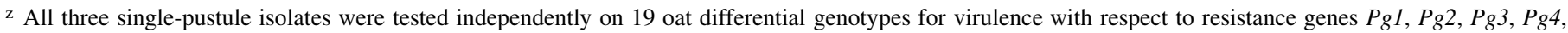
Pg8, Pg9, Pg10, Pg13, Pg15, Pg16, Pg17, PgSaia, and PgA and the susceptible cultivar Swan. 
QTL mapping. QTL analysis was performed on the three mapping populations using MapQTL 6 software (Van Ooijen 2009), using VIS and IF (Jafary et al. 2006), both averaged over the two experiments per mapping population-isolate combination. Mapping consisted of three subsequent steps (Qi et al. 1998). First, interval mapping was used to detect putative QTL (logarithm of odds [LOD] > 3). Markers with the highest LOD values (peak markers) were taken to serve as cofactors in subsequent multiple QTL model (MQM) mapping. When LOD values of some markers on other regions reached the significance level, the MQM was repeated after adding those new peak markers as cofactors, and when LOD values for other markers dropped to lower than the significance level, cofactors were dropped until a stable LOD profile was reached. Finally, restricted MQM mapping using the cofactor markers of the final MQM run was performed. In all methods, a LOD threshold of three was used to declare QTL as significant.

Comparing QTL. To compare QTL positions between linkage maps, the LOD-1 support intervals and peak markers were marked on the high-density integrated genetic map posted on the GrainGenes website (http://wheat.pw.usda.gov) (Aghnoum et al. 2010). The Aghnoum et al. (2010) integrated map is based on restriction fragment length polymorphisms (20\%), amplification fragment length polymorphisms (AFLP) (20\%), simple sequence repeats (SSR) (9\%), diversity arrays technology (DArT) (19\%), and transcript-derived (TDM) markers. On the integrated map, QTL for partial resistance to leaf rust ( $P$. hordei) and nonhost resistance to various heterologous rusts are indicated, enabling comparison of QTL positions to different rust species and isolates (Jafary et al. 2008; Niks et al. 2015). The QTL positions in the Vada $\times$ SusPtrit and Cebada Capa $\times$ SusPtrit linkage maps were converted to the positions on the integrated map of Aghnoum et al. (2010). QTL regions associated with resistance to different isolates or in different populations, or both, were considered to be the same if there was overlap between their LOD-1 support intervals on the integrated map.

The SusPtrit $\times$ Golden Promise genetic map had been constructed on the basis of whole-genome genotyping (TraitGenetics $\mathrm{GmbH}$, Gatersleben, Germany), using an ILLUMINA iSelect 9k barley Infinium chip that carries 7,864 single nucleotide polymorphisms (SNP) (Yeo et al. 2014). The SusPtrit $\times$ Golden Promise map could not be integrated into the consensus map of Aghnoum et al. (2010), due to the paucity of markers in common. Thus, it was not straightforward to place the SNP peak markers in the SusPtrit $\times$ Golden Promise population on the integrated map that was used for Vada $\times$ SusPtrit and Cebada Capa $\times$ SusPtrit. Each SNP peak marker in SusPtrit $\times$ Golden Promise was assessed to determine whether it was polymorphic in Vada $\times$ SusPtrit or in Cebada Capa $\times$ SusPtrit. For each of these two mapping populations, 87 RILs had been genotyped on the same ILLUMINA chip as was used for SusPtrit $\times$ Golden Promise. If the population was polymorphic for the relevant SusPtrit $\times$ Golden Promise marker, we identified the AFLP marker that, for those 87 RILs, cosegregated best with the SNP marker.

Histology of the resistance. Six seedlings, each, of SusPtrit, Vada, Cebeco (oat), and Alfred (oat) were inoculated with P. graminis f. sp. avenae isolate Evertsholm. Six days after inoculation, four leaf samples per accession, each about $3 \mathrm{~cm}$ long, were collected. The two remaining seedlings were used to record macroscopic infection types. The collected leaf samples were then stained with Uvitex-B, as described previously (Hoogkamp et al. 1998; Niks 1982), to evaluate development stage and size of 50 infection units per leaf sample, under a Zeiss Axiophot photo microscope with an aniline blue filter. The infection units were classified into three development classes based on the classification by Niks and Kuiper (1983): nonpenetrating appressoria, aborted substomatal vesicles, early aborted (EA) colonies (with six or less haustorial mother cells) without or with necrosis, and established (EST) colonies (branched hyphae with more than six haustorial mother cells) with or without necrosis. The latter group included Niks and Kuiper's (1983) class of successful colonies, since it was not possible to judge which infection units, at a later sampling time, might have succeeded to produce spores. Within the EA and EST colony classes, we recorded whether infection units were associated with necrotic plant cells. Such necrosis was visible as autofluorescence in plant cells.

The rationale of the recording is the following (Niks 1982, 1983; Niks and Kuiper 1983). Of all infection units that penetrate, a proportion is arrested within about $24 \mathrm{~h}$ after inoculation (EA), while the remaining establish a feeding relationship to support at least some growth and development of mycelium (EST). These established infection units should have formed at least some haustoria. Some $R p h$ genes act very early and cause EA just during the formation of the very first haustoria (Niks and Kuiper 1983). This resistance appears as a high proportion of EA with high association with plant cell necrosis. Other types of resistance, i.e., partial resistance and nonhost resistance, typically reduce the success in haustorium formation, causing high EA essentially without necrosis of plant cells (Niks 1982; Niks and Kuiper 1983). Late acting $R p h$ genes arrest mycelial colonies after establishment, also with association with plant cell necrosis. Partial and nonhost resistance also strongly reduce mycelial growth but, typically, as with EA, with very little plant cell necrosis. Therefore, we take (i) a high proportion of EA with hardly any plant cell necrosis and (ii) strongly reduced growth of those infection units that get established with necrosis as markers for prehaustorial resistance mechanisms, and we take EA and EST with strong association with plant cell necrosis as markers for posthaustorial resistance. Low proportions of EA and large size of EST colonies are interpreted as indication for high susceptibility.

The experiment was repeated twice. Per accession, the results are based on approximately 50 infection units $\times 4$ leaf samples $\times 2$ replicates $=400$ infection units. The percentage of nonpenetrating infection units was calculated by dividing the number of nonpenetrants by the total number of infection units. The proportion of the early abortion class was obtained by dividing the number of EA infection units by the total number of infection units that were EA or established.

\section{RESULTS}

Host status of barley with respect to $P$. graminis f. sp. avenae. Sixty-six diverse barley accessions were inoculated with two P. graminis f. sp. avenae SP isolates (Evertsholm and Ingeberga) to quantify the host status of barley to $P$. graminis $\mathrm{f} . \mathrm{sp}$. avenae, identify possible isolate-specific phenotypic responses in barley, and to compare the responses to other previously tested heterologous rusts (Atienza et al. 2004). The phenotypic data indicated that $89 \%$ (Evertsholm) and 59\% (Ingeberga) of the barley

TABLE 2. Susceptibility scores (0 to 5) for eight heterologous rust pathogens and adapted Puccinia hordei tested on diverse barley accessions

\begin{tabular}{|c|c|c|c|c|c|c|}
\hline \multirow[b]{2}{*}{ Pathogen } & \multicolumn{6}{|c|}{ Susceptibility score ${ }^{y}$} \\
\hline & 0 & 1 & 2 & 3 & 4 & 5 \\
\hline P. agropyrina & 39 & 7 & 9 & 37 & 8 & 0 \\
\hline P. triticina Flamingo & 56 & 10 & 20 & 13 & 3 & 0 \\
\hline P. hordei-secalini & 30 & 37 & 9 & 16 & 7 & 1 \\
\hline P. graminis f. sp. lolii & 72 & 0 & 15 & 11 & 3 & 0 \\
\hline P. hordei-murini Rhenen & 59 & 27 & 3 & 3 & 8 & 0 \\
\hline P. coronata $\mathrm{f} . \mathrm{sp}$. avenae & 67 & 29 & 4 & 0 & 0 & 0 \\
\hline P. graminis f. sp. avenae (Evertsholm $)^{\mathrm{z}}$ & 89 & 5 & 1 & 5 & 0 & 0 \\
\hline$P$. graminis $\mathrm{f} . \mathrm{sp}$. avenae $\left(\right.$ Ingeberga) ${ }^{\mathrm{z}}$ & 59 & 11 & 13 & 17 & 0 & 0 \\
\hline P. hordei & 3 & 0 & 0 & 5 & 66 & 26 \\
\hline
\end{tabular}

y Susceptibility score (per leaf): 0 , immune or near immune (less than three pustules and few flecks); 1, less than three pustules and medium or many flecks; 2, three to 10 pustules; 3, 10 to 100 pustules; 4, more than 100 pustules; 5 , more than 500 pustules.

$\mathrm{z}$ The phenotypic data (percentage of lines with the different susceptibility scores) for $P$. graminis f. sp. avenae is based on the assessment on a subset of 66 barley accessions as described by Atienza et al. (2004) 
accessions did not allow pustule formation at the seedling stage, indicating that barley is a near-nonhost to $P$. graminis $\mathrm{f}$. sp. avenae (Table 2). High susceptibility (scores of 4 or 5) was not observed in response to either the Evertsholm or Ingeberga isolates, in contrast to scores obtained with the adapted $P$. hordei and some other heterologous rust pathogens (Table 2). More of the barley accessions were (near) immune to the $P$. graminis f. sp. avenae isolate Evertsholm ( $89 \%$ score 0$)$ than to other heterologous rust pathogens, including the Ingeberga isolate (59\% score 0$)$. Hence, pathotype specificity was observed for $P$. graminis f. sp. avenae on barley. The isolate-specific character of the resistance was observed for barley accessions SusPtrit (Fig. 1; Table 2), SusPmur, and Trigo Biasa (data not shown) that were resistant (pinpoint flecks), scoring 0 with Evertsholm and 3 for Ingeberga. Such isolate specificity may reflect a shared $R$ gene in Trigo Biasa and other related accessions. Indeed, Trigo Biasa was one of the ancestors of SusPtrit (Atienza et al. 2004).

Genetic analysis of resistance. All SP isolates used in this study differed with respect to their virulence on 19 Australian oat stem rust differential genotypes (Table 1). The parental lines Vada and Golden Promise were immune to the three SP isolates of $P$. graminis f. sp. avenae, whereas Cebada Capa was immune to $P$. graminis f. sp. avenae isolate Evertsholm but resistant (few pustules and flecks) to Pattala and Ingeberga (Table 1). SusPtrit was moderately susceptible to isolate Ingeberga, moderately resistant to Pattala, and highly resistant to isolate Evertsholm (Fig. 1A, 1B and 1C). Resistance in SusPtrit in response to isolate Evertsholm was associated with many pinpoint flecks of less than $0.5 \mathrm{~mm}$ in diameter (Fig. 1A). Remarkably, isolate Ingeberga had a strong tendency to produce many more telia than uredinia on barley seedlings (Fig. 1B) but not on oat seedlings (Fig. 1D). In all experiments, the susceptible oat control Cebeco was heavily infected by all $P$. graminis f. sp. avenae isolates.

Seedlings of all three barley mapping populations, Vada $\times$ SusPtrit, Cebada Capa $\times$ SusPtrit, and SusPtrit $\times$ Golden Promise, were phenotyped for VIS and IF with all three $P$. graminis $\mathrm{f}$. sp. avenae isolates. Two experimental replicates were performed for each mapping population-isolate combination, and in all cases, a positive correlation of 0.7 was observed between the two replicates. In experiments with $P$. graminis f. sp. avenae isolate Pattala and Ingeberga, SusPtrit was the more or less susceptible parent in all three mapping populations and segregation for VIS and IF was observed, including, in some populations, the presence of some lines that were more heavily infected than SusPtrit (Fig. 2). VIS (Fig. 2) and IFs (data not shown) observed in the mapping populations inoculated with Pattala and Ingeberga indicated continuous variation, where the level and characteristics of infection ranged from complete immunity to a similar or higher number of flecks and pustules than observed on SusPtrit (Fig. 2). This continuous unimodal variation suggests polygenic inheritance. Because all parental genotypes were either resistant or immune to the Evertsholm isolate, segregation in the mapping populations would only occur if the parents did not share one or more major-effect resistance genes. No segregation was observed for reaction to Evertsholm in the Cebada Capa $\times$ SusPtrit and SusPtrit $\times$ Golden Promise mapping populations, but $25 \%$ of the RILs of the Vada $\times$ SusPtrit mapping population allowed at least one sporulating pustule per leaf (Fig. 2G). This segregation suggests that the resistance of Vada to isolate Evertsholm is based on one or more different genes than the resistance of SusPtrit.

QTL analysis of mapping populations. In total, nine chromosomal regions were associated with resistance to at least one isolate of P. graminis f. sp. avenae (Rpgaq1 to Rpgaq9) (Table 3; Fig. 3). Two resistance QTL were mapped in two populations and were contributed by Vada and Golden Promise (Rpgaq1) or by Vada and Cebada Capa (Rpgaq2). For one QTL, detected in Vada $\times$ SusPtrit (Rpgaq5), the resistance allele was contributed by SusPtrit. Four resistance QTL were effective to one isolate and five were effective to two or three isolates. The QTL on $1 \mathrm{H}$ (Rpgaq1) had a major phenotypic effect (up to $27 \%$ of phenotypic variance), was identified in Vada $\times$ SusPtrit and SusPtrit $\times$ Golden Promise but not in the Cebada Capa $\times$ SusPtrit mapping population, and was effective to all isolates tested. On the long arm of chromosome $2 \mathrm{H}$, two resistance loci were identified (Rpgaq2 and Rpgaq9) (Table 3; Fig. 3). Rpgaq2 was contributed by Vada and Cebada Capa and was effective to both Ingeberga and Pattala isolates. In contrast, Rpgaq9 was only identified in the Golden Promise parent and was detected only with the Ingeberga isolate. The QTL Rpgaq5, at the telomeric region of 7HS for which the resistance allele was contributed by SusPtrit, had a much stronger effect against isolate Evertsholm than to Pattala and had no significant effect against isolate Ingeberga (Table 3). RILs containing the SusPtrit allele of the peak marker had, on average, 5.5 pustules or flecks per seedling leaf, those with the Vada allele had, on average, 43 pustules or flecks with Evertsholm. This contrast was 15 versus 25 for isolate Pattala, respectively. Together, these results indicate
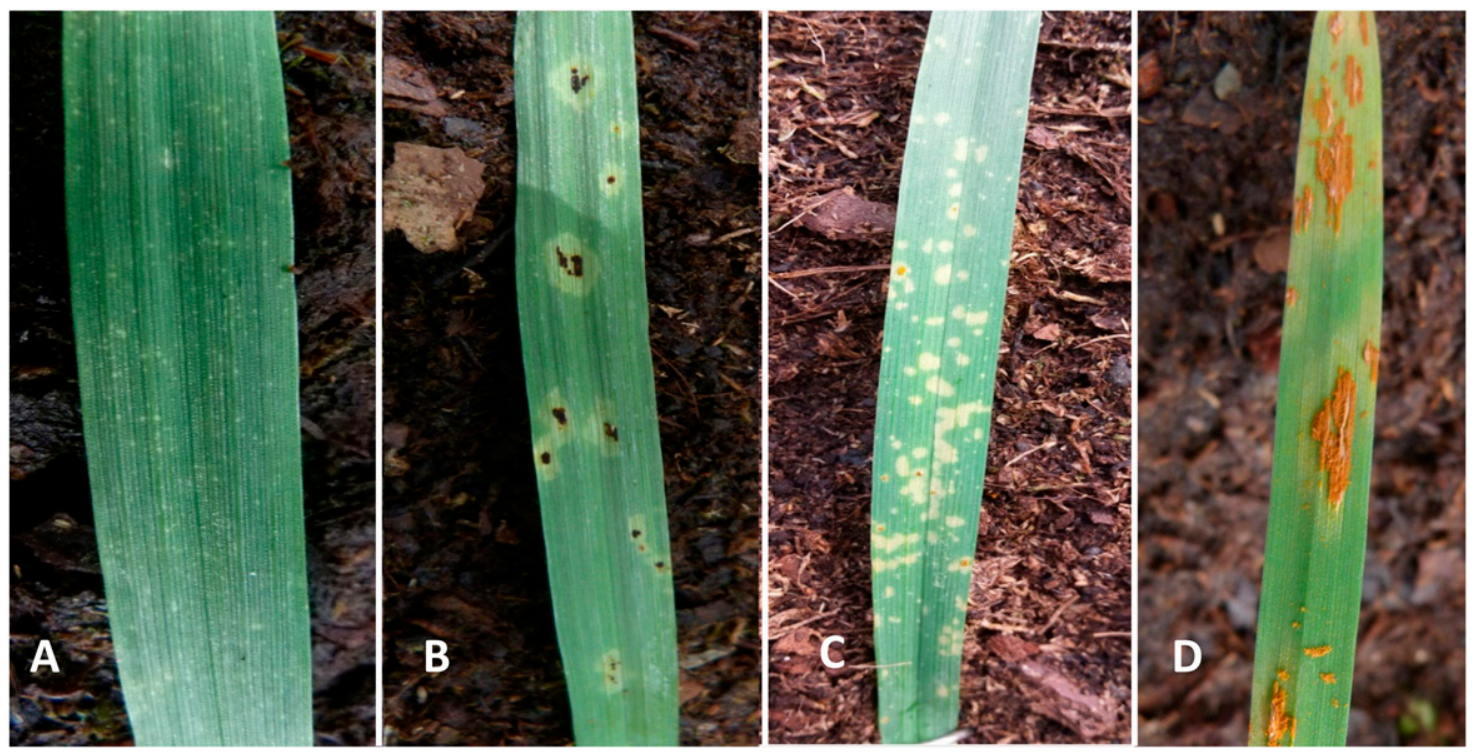

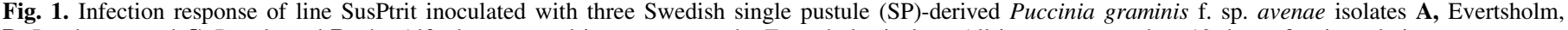
$\mathbf{B}$, Ingeberga, and $\mathbf{C}$, Pattala and $\mathbf{D}$, the Alfred oat control in response to the Evertsholm isolate. All images were taken 12 days after inoculation. 

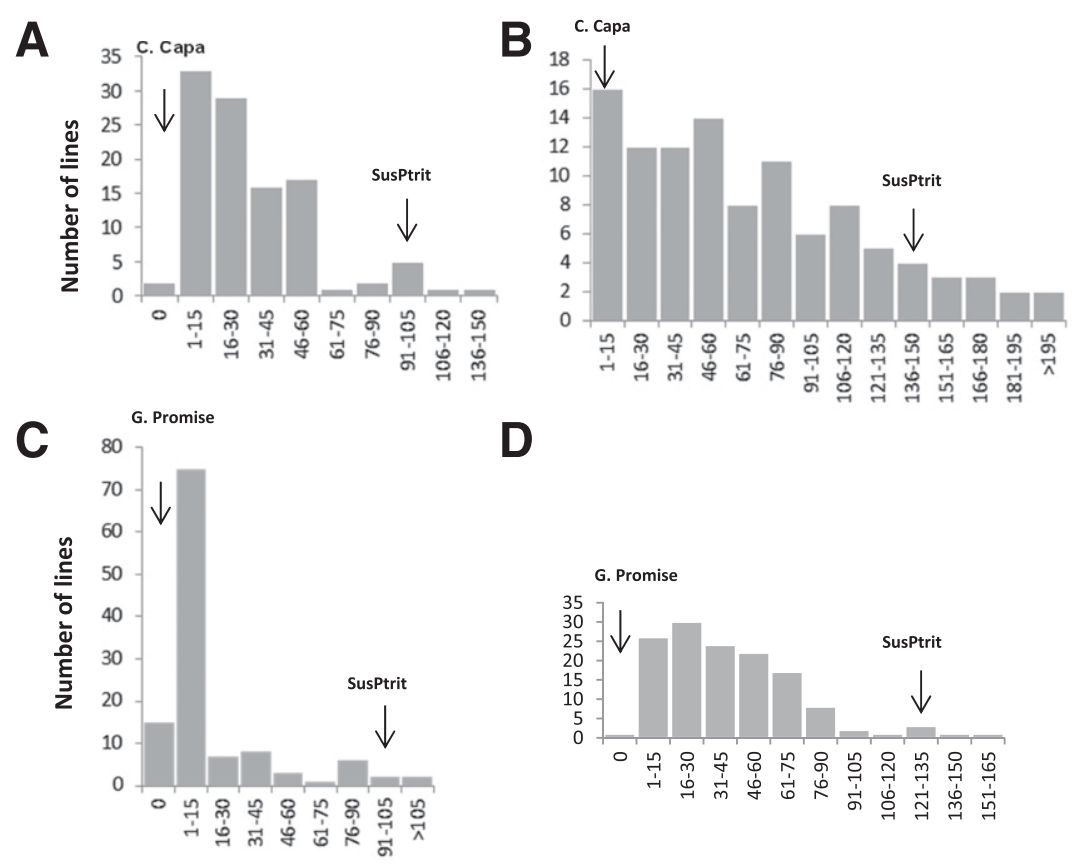

D
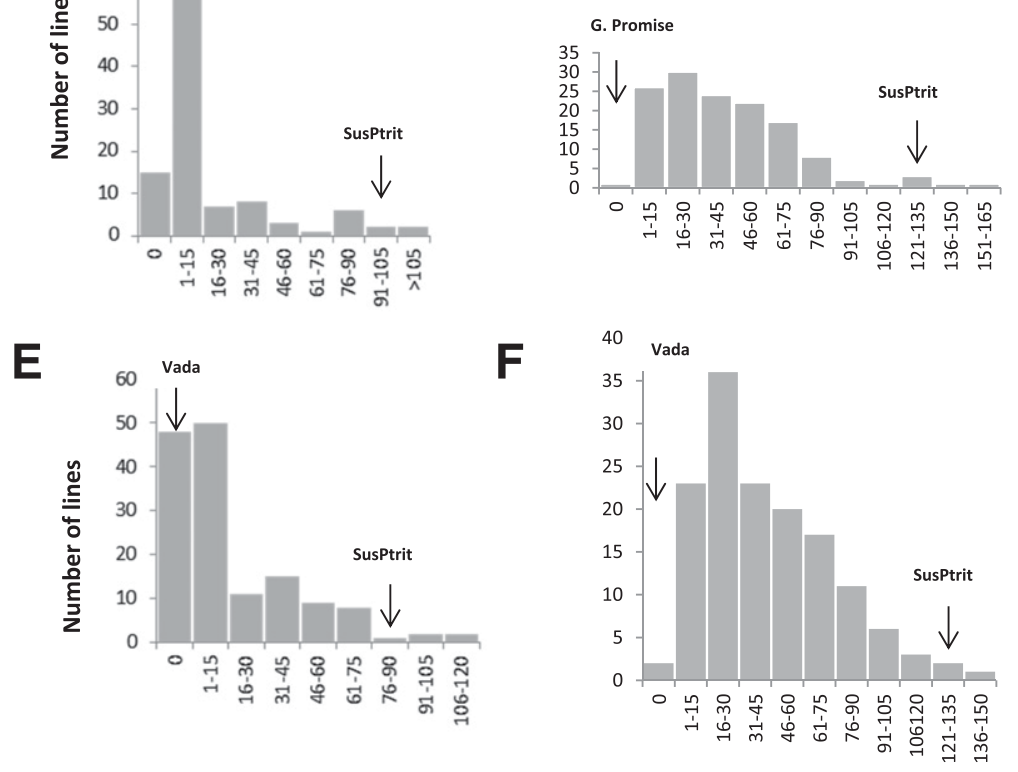

Visible Infection Sites

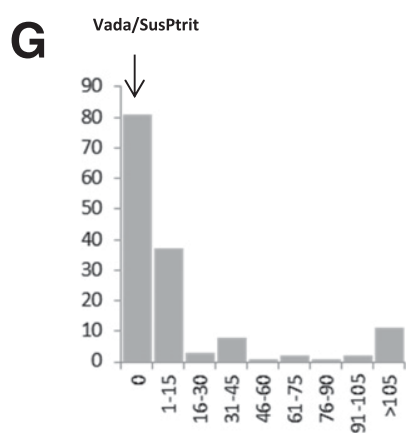

Visible Infection Sites

Fig. 2. Frequency distribution of the visible infection site (VIS) phenotype for resistance to three single pustule-derived Puccinia graminis f. sp. avenae isolates. A, C, and E, Pattala, B, D, and F, Ingeberga, and G, Evertsholm in barley mapping populations Cebada Capa $\times$ SusPtrit (A and B), SusPtrit $\times$ Golden Promise $(\mathrm{C}$ and $\mathrm{D})$, and Vada $\times$ SusPtrit $(\mathrm{E}$ to G). Only data for the Vada $\times$ SusPtrit mapping population is presented for the Evertsholm isolate. Values of the two parental lines are shown by arrows.

TABLE 3. Significant quantitative trait loci (QTL) conferring resistance to one to three Puccinia graminis f. sp. avenae isolates ${ }^{\mathrm{w}}$

\begin{tabular}{|c|c|c|c|c|c|c|c|c|}
\hline QTL designation & Population & Isolate & Linkage group & Position $(\mathrm{cM})^{\mathrm{x}}$ & Peak marker & LOD $^{y}$ & $\% \operatorname{Exp}^{\mathrm{z}}$ & Donor of resistance allele \\
\hline Rpgaq1 & $\mathrm{V} \times \mathrm{S}$ & Evertsholm & $1 \mathrm{H}$ & 53 & E33M54-263 & 5.05 & 12.5 & Vada \\
\hline Rpgaq1 & $\mathrm{V} \times \mathrm{S}$ & Ingeberga & $1 \mathrm{H}$ & 53 & E33M54-263 & 5.43 & 11.5 & Vada \\
\hline Rpgaq1 & $\mathrm{V} \times \mathrm{S}$ & Pattala & $1 \mathrm{H}$ & 53 & E33M54-263 & 12.5 & 22.7 & Vada \\
\hline Rpgaq1 & $\mathrm{S} \times \mathrm{GP}$ & Pattala & $1 \mathrm{H}$ & 56.8 & BOPA2_12_10314 & 8.27 & 27.6 & Golden Promise \\
\hline Rpgaq 2 & $\mathrm{~V} \times \mathrm{S}$ & Ingeberga & $2 \mathrm{H}$ & 87 & E33M61-227 & 3.64 & 7.5 & Vada \\
\hline Rpgaq2 & $\mathrm{V} \times \mathrm{S}$ & Pattala & $2 \mathrm{H}$ & 87 & E33M61-227 & 4.45 & 7.1 & Vada \\
\hline Rpgaq2 & $\mathrm{CC} \times \mathrm{S}$ & Ingeberga & $2 \mathrm{H}$ & 135.3 & E33M51-121 & 4.33 & 15.6 & Cebada Capa \\
\hline Rpgaq3 & $\mathrm{V} \times \mathrm{S}$ & Pattala & $6 \mathrm{H}$ & 54 & E35M55-217 & 4.19 & 6.6 & Vada \\
\hline Rpgaq4 & $\mathrm{V} \times \mathrm{S}$ & Ingeberga & $7 \mathrm{H}$ & 126 & E35M61-256 & 3.49 & 7.2 & Vada \\
\hline Rpgaq4 & $\mathrm{V} \times \mathrm{S}$ & Pattala & $7 \mathrm{H}$ & 118 & E33M61-184 & 3.4 & 6.1 & Vada \\
\hline Rpgaq5 & $\mathrm{V} \times \mathrm{S}$ & Evertsholm & $7 \mathrm{H}$ & 6 & E37M50-435 & 5.37 & 13.4 & SusPtrit \\
\hline Rpgaq5 & $\mathrm{V} \times \mathrm{S}$ & Pattala & $7 \mathrm{H}$ & 6 & E37M50-435 & 5.04 & 8.8 & SusPtrit \\
\hline Rpgaq6 & $\mathrm{CC} \times \mathrm{S}$ & Pattala & $3 \mathrm{H}$ & 157.4 & E35M61-71 & 3.14 & 8.7 & Cebada Capa \\
\hline Rpgaq7 & $\mathrm{CC} \times \mathrm{S}$ & Ingeberga & $6 \mathrm{H}$ & 80.4 & E38M54-401 & 3.32 & 11.7 & Cebada Capa \\
\hline
\end{tabular}

${ }^{\text {w }}$ Population refers to the respective mapping populations used in this study abbreviated as follows: Vada $\times$ SusPtrit $(\mathrm{V} \times \mathrm{S}), \mathrm{Cebada}$ Capa $\times$ SusPtrit $(\mathrm{CC} \times \mathrm{S})$, and SusPtrit $\times$ Golden Promise $(\mathrm{S} \times \mathrm{GP})$.

${ }^{x}$ Centimorgan position on the biparental linkage map.

${ }^{y}$ LOD $=$ logarithm of odds.

${ }^{\mathrm{z}}$ Percentage of the explained phenotypic variance. 
that barley genotypes share some common resistance genes to $P$. graminis f. sp. avenae and that some of the resistance genes are isolate-specific. QTL mapping on the basis of IF instead of VIS gave similar results but lower LOD scores and no other QTL than discovered by mapping on the basis of VIS. Those mapping results are not presented here.

Comparison of Rpgaq loci with previously mapped QTL to rust pathogens. The consensus map permitted comparisons of the identified Rpgaq loci with previously mapped QTL for resistance to other rust pathogens (Jafary et al. 2006, 2008; Niks et al. 2015; Yeo et al. 2014) in the same mapping populations. We considered two QTL detected for different rusts to colocalize when their LOD-1 support intervals overlapped and they were contributed by the same parental line. With the exception of Rpgaq7 and Rpgaq9, all Rpgaq loci colocated with previously identified QTL for resistance to heterologous rust pathogens, as summarized in
Table 4. Five Rpgaq loci colocated with previously identified resistance QTL to more than one Puccinia species, while Rpgaq5 and Rpgaq6 colocated with resistance QTL to P. triticina and $P$. coronata (derived from Elymus repens), respectively. Interestingly, Rpgaq3 colocated with resistance QTL to two other different $P$. graminis formae speciales and $P$. triticina.

Pre- and posthaustorial resistance to $P$. graminis f. sp. avenae. Microscopic examination of infected leaf samples of Vada and SusPtrit and two oat accessions, Cebeco and Alfred, indicated that $P$. graminis $\mathrm{f}$. sp. avenae urediniospores were able to germinate, locate stomata, and produce appressoria, substomatal vesicles, and infection hyphae on all accessions (Fig. 4). The percentage of stomatal exclusion (appressoria unable to penetrate the stoma on which they formed) varied from 20 to $77 \%$. In both replications, Alfred oat had a significantly higher frequency of appressoria that failed to penetrate stomata than Cebeco and the resistant barley
$1 \mathrm{H}$

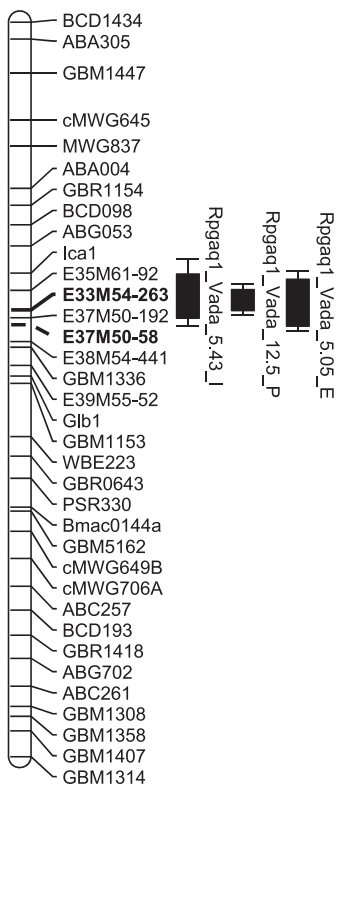

$2 \mathrm{H}$

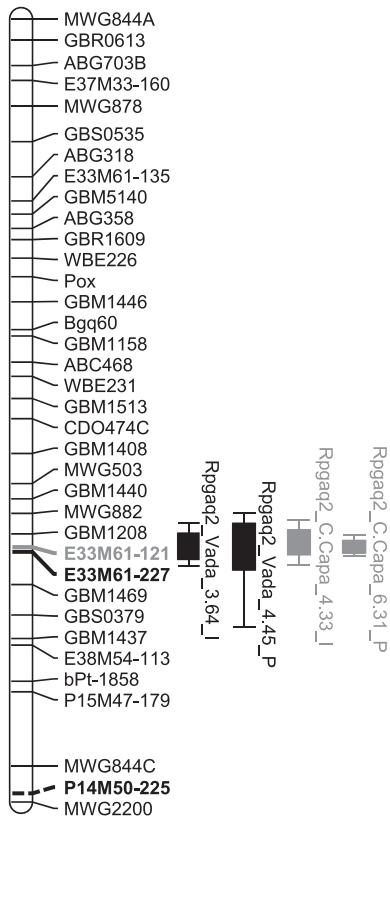

$3 \mathrm{H}$

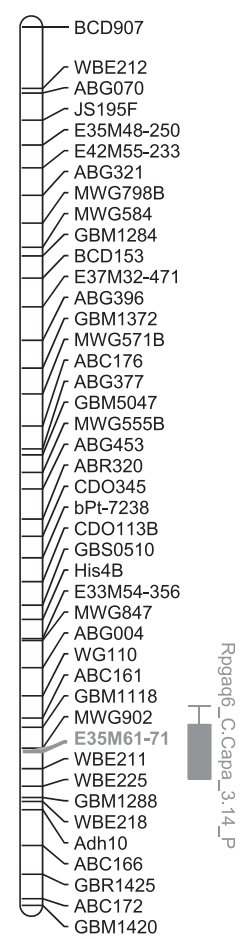

$6 \mathrm{H}$

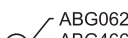

$\Upsilon_{\text {ABG466 }}^{A B}$

ABG378
E42M54-160

E33M61-40

- E33M55-63

- $\mathrm{GBM1270}$

- DD1.1C

- E35M61-269

$={ }_{\text {iLdh1 }}^{\mathrm{E35M}}$

- E36M50-1

WBE215

GBS0468

GBMS180

E38M54-401

ABC170B

GBS0767

E39M61-66

GBR0621

- Tef1

- scssr00103

- E32M55-102

- Bmac0040a

P16M51-215
E42M48-380

GBM1154

GBM1274

GBM1274
MWG2196

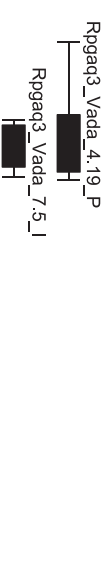

$7 \mathrm{H}$

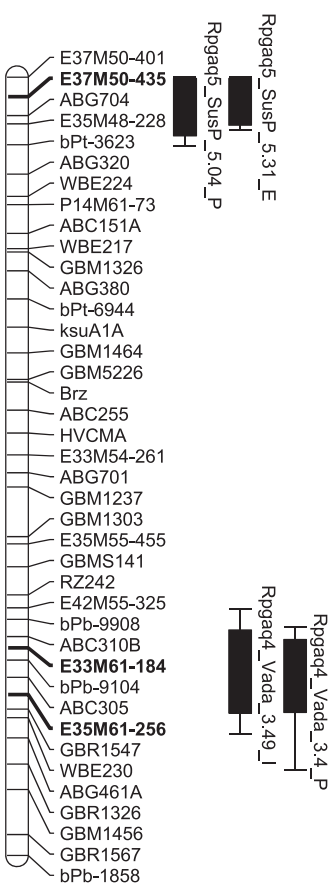

Fig. 3. Integrated linkage map of barley (Aghnoum et al. 2010) showing the quantitative trait loci (QTL) for resistance to three Swedish Puccinia graminis f. sp. avenae isolates in the Vada $\times$ SusPtrit (black) and Cebada Capa $\times$ SusPtrit (gray) mapping populations. The position of the most closely associated markers (bold dashed) with the corresponding QTL identified in the SusPtrit $\times$ Golden Promise mapping population were placed on the integrated map. The names on the QTL bars have four components: the provisional name of the gene at the QTL, donor, logarithm of odds (LOD) value, and the P. graminis f. sp avenae isolate used to map the specific QTL (I for Ingeberga, P for Pattala, and E for Evertsholm). The ruler on the left side indicates the distances in centiMorgans. The length of the shaded solid bars indicates the LOD-1 confidence intervals (with their corresponding peak markers in the same shade), while the QTL lines are extended to the LOD-2 confidence intervals.

TABLE 4. Summary of resistance quantitative trait loci (QTL) identified in this study and their colocation to previously mapped QTL in response to other rust pathogens

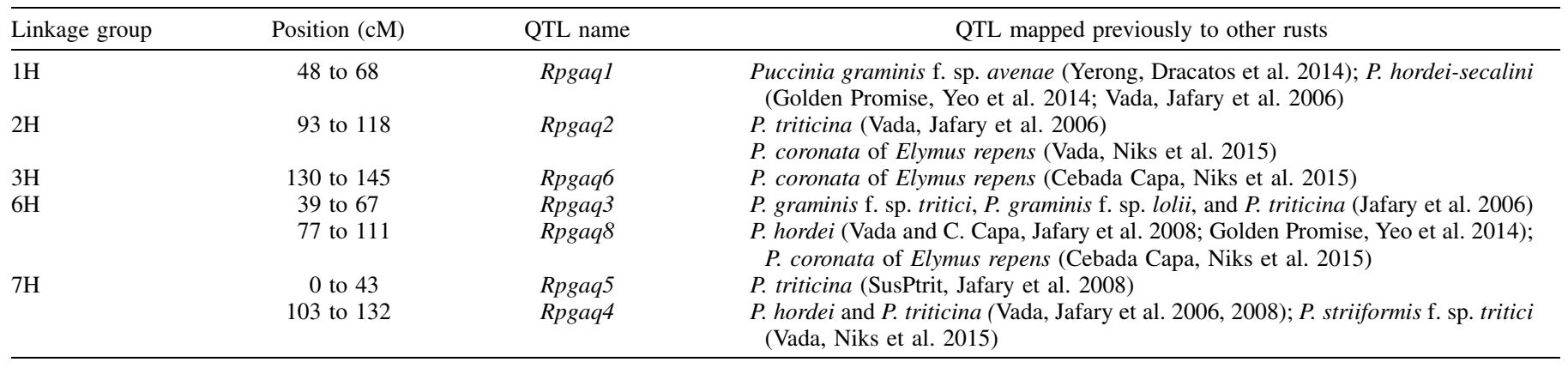


genotypes. Percentage of aborted substomatal vesicles was nil (data not presented). Immunity in Vada was mainly due to prehaustorial resistance, as only $15 \%$ of the penetrating infection units established branched mycelial colonies (Fig. 4; Table 5). Necrosis did not play an obvious role in the immunity of Vada but was present in at least $64 \%$ of the established infection units in SusPtrit. The average diameter of established colonies on barley were about $10 \times$ smaller that on the susceptible oat reference cultivars (Fig. 4; Table 5).

\section{DISCUSSION}

Host status and histology of barley to $P$. graminis f. sp. avenae relative to oat. Different formae speciales of Puccinia graminis have coevolved with their respective grass hosts, presumably through the development or acquisition of effectors that permit the establishment of a compatible interaction. $P$. graminis f. sp. tritici mainly infects cereals within the family Triticeae, while $P$. graminis f. sp. avenae is specialized mainly to Avena spp. and other grasses within the Pooideae subtribe (Leonard and Szabo 2005). Barley is a host to $P$. graminis f. sp. tritici and $P$. graminis f. sp. secalis but is not considered a host to $P$. graminis f. sp. avenae or $P$. graminis f. sp. lolii. Barley is deemed a nearnonhost to numerous heterologous rust pathogen species, based on observed seedling susceptibility in a small proportion of a collection of 110 diverse barley accessions to various rust species, including P. graminis f. sp. lolii and P. triticina (Atienza et al. 2004). The data
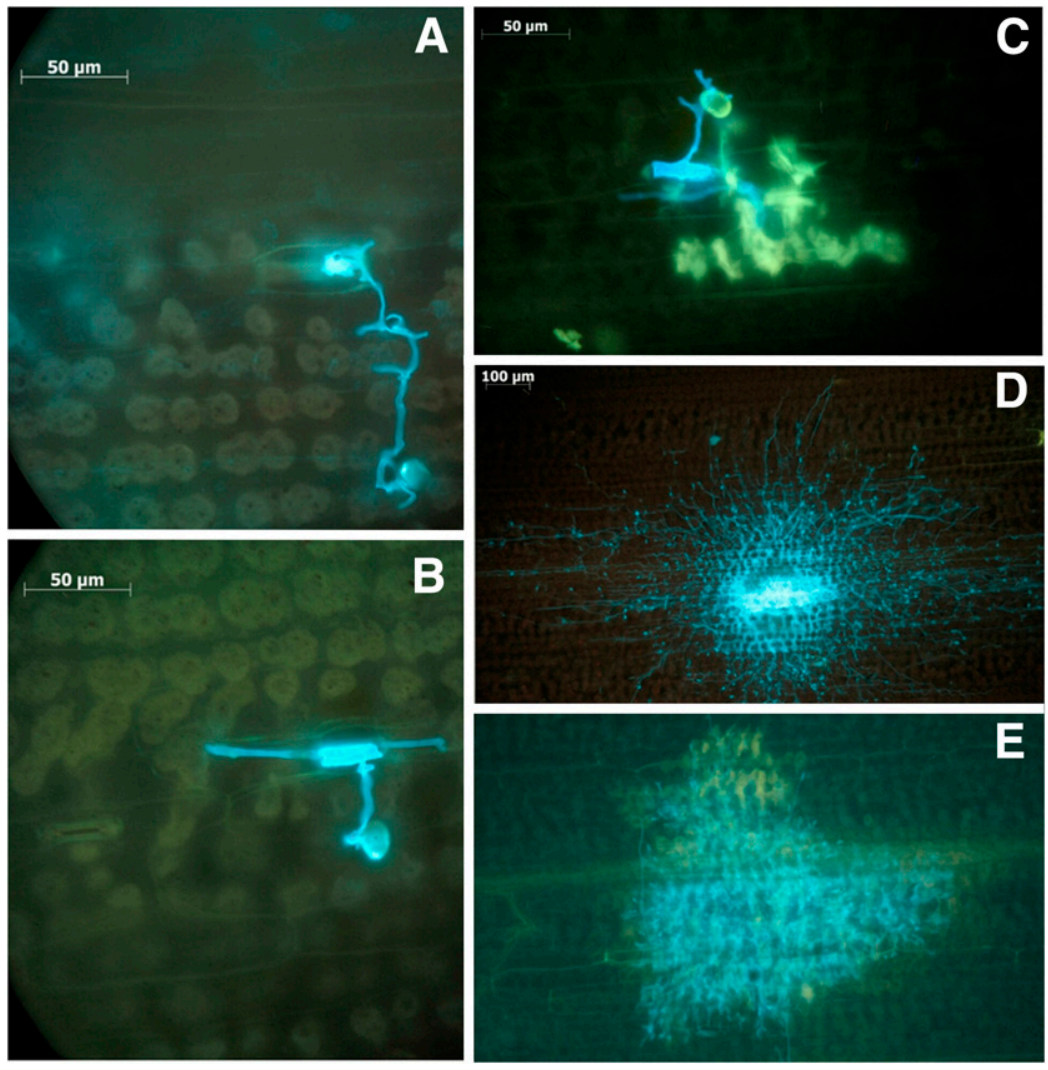

Fig. 4. Histological analysis of the development stages of infection using the Puccinia graminis f. sp. avenae-Evertsholm isolate. A, Nonpenetrating infection unit on Alfred oat. B, Early abortion without necrosis on Vada. C, Early abortion with necrosis on SusPtrit. D, Established colony without necrosis on Cebeco oat. E, Established colony with necrosis on SusPtrit.

TABLE 5. Average proportion of infection units ${ }^{\mathrm{x}}$ of Puccinia graminis f. sp. avenae at three development stages on barley and oat leaf segments collected 6 days after inoculation

\begin{tabular}{|c|c|c|c|c|c|c|c|}
\hline \multirow[b]{2}{*}{ Rep } & \multirow[b]{2}{*}{ Accession } & \multirow[b]{2}{*}{ Phenotype } & \multirow[b]{2}{*}{ Nonpen } & \multirow[b]{2}{*}{ EA $(+N)^{y}$} & \multirow[b]{2}{*}{$\operatorname{EST}(+N)^{z}$} & \multicolumn{2}{|c|}{ Colony diameter $(\mu \mathrm{m})$} \\
\hline & & & & & & $(-\mathrm{N})$ & $(+\mathrm{N})$ \\
\hline 1 & Vada & Immune & $0.32 \mathrm{a}$ & $0.85(0) \mathrm{a}$ & $0.15(0)$ & 7.12 & $\ldots$ \\
\hline 1 & SusPtrit & Resistant & $0.28 \mathrm{a}$ & $0.69(0.04) b$ & $0.31(0.64)$ & 8.31 & 11.4 \\
\hline 1 & Alfred (oat) & Very susceptible & $0.77 b$ & $0.11(0) \mathrm{c}$ & $0.89(0)$ & 85.64 & $\ldots$ \\
\hline 1 & Cebeco (oat) & Very susceptible & $0.35 \mathrm{a}$ & $0.10(0) \mathrm{c}$ & $0.90(0)$ & 77.12 & $\ldots$ \\
\hline 2 & Vada & Immune & $0.27 \mathrm{a}$ & $0.84(0) \mathrm{a}$ & $0.16(0)$ & 6.33 & $\ldots$ \\
\hline 2 & SusPtrit & Resistant & $0.2 \mathrm{a}$ & $0.40(0) \mathrm{b}$ & $0.60(0.71)$ & 9.13 & 8.97 \\
\hline 2 & Alfred (oat) & Very susceptible & $0.57 b$ & $0.05(0) \mathrm{c}$ & $0.95(0)$ & 84.64 & $\ldots$ \\
\hline 2 & Cebeco (oat) & Very susceptible & $0.42 \mathrm{a}$ & $0.03(0) \mathrm{c}$ & $0.97(0)$ & 84.72 & $\ldots$ \\
\hline
\end{tabular}

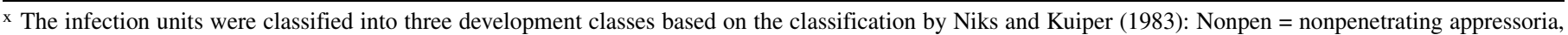
$\mathrm{EA}=$ early aborted colonies (with six or less haustorial mother cells) without or with necrosis, EST = established colonies (branched hyphae with more than six haustorial mother cells) with or without necrosis. The latter group included Niks and Kuiper's (1983) class of successful colonies, since it was not possible to judge which infection units at later sampling times might have succeeded to produce spores. Colony diameter was measured at magnification of $40 \times$. Rep $=$ replicate. Values in each column followed by the same letter are not significantly different $(P \leq 0.05)$, according to Duncan's multiple range test.

y The values in brackets are average proportions of EA germlings associated with necrosis.

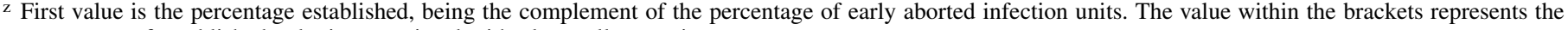
percentage of established colonies associated with plant cell necrosis. 
in the present study suggest that barley is also a near-nonhost to $P$. graminis f. sp. avenae. The proportion of moderately susceptible barley accessions (11\%) to $P$. graminis f. sp. avenae from the subset of 66 barleys used by Atienza et al. (2004) was comparable to the proportion previously observed to be somewhat susceptible to $P$. triticina and P. graminis f. sp. lolii. As reported previously by Dracatos et al. (2014) and as is the case for the other previously tested heterologous rust pathogens, none of the 66 barley accessions were as susceptible as the susceptible oat control Cebeco to either isolate of $P$. graminis f. sp. avenae.

Histological analysis using the Evertsholm isolate indicated that $P$. graminis f. sp. avenae was able to penetrate stomata on both Vada (immune) and SusPtrit barley (completely resistant) at the same frequency as on the highly susceptible oat cultivar Cebeco. Although largely susceptible, the observed stomatal exclusion in Alfred oat may represent a partial host resistance mechanism to P. graminis f. sp. avenae. Kochman and Brown (1975) identified different levels of stomatal exclusion between oat accessions to $P$. graminis f. sp. avenae.

Our data demonstrated that a substantial proportion of established colonies in SusPtrit were associated with a hypersensitivity reaction, suggesting that the resistance gene at $7 \mathrm{H}$ may represent a common $R$ gene-mediated resistance mechanism. However, since we did not compare lines that were near-isogenic for the QTL that were discovered, we cannot attribute the hypersensitive reaction in SusPtrit to a particular gene for resistance. The observed high frequency of EA infection units and finding that at least $29 \%$ of the established colonies in SusPtrit were not associated with hypersensitivity, indicates that, not only in Vada but also in SusPtrit, prehaustorial resistance plays an important role. This suggests that failed haustorium formation is likely to be a major component of the resistance of barley to $P$. graminis $\mathrm{f}$. $\mathrm{sp}$. avenae. High failure rates in haustorium formation is a hallmark of nonhost resistance of plants to rust and powdery mildew fungi (Niks and Marcel 2009; Niks and Rubiales 2002). It is supposed that much of nonhost resistance is explained by pathogen-associated molecular pattern (PAMP)triggered immunity, which cannot be suppressed by a heterologous pathogen's effectors (Niks and Marcel 2009). Cloning of the resistance genes discovered in this study in SusPtrit and Vada may be of great interest to understand the molecular basis of nonhost resistance.

Polygenic inheritance of resistance to $P$. graminis f. $\mathbf{s p .}$ avenae in barley. Both simple and complex inheritance of nearnonhost resistance has been reported in various cereal-Puccinia pathosystems. Some studies of near-nonhost resistance in wheat to the barley crown rust and barley stripe rust pathogens determined that the resistance was simply inherited and mostly due to single dominant genes (Niu et al. 2014; Rodriguez et al. 2004). The inheritance of resistance to $P$. graminis f. sp. avenae in barley was previously found to be simply inherited and was attributed to a single dominant gene (Dracatos et al. 2015; Martens et al. 1983). In contrast, our data demonstrated that near-nonhost resistance to $P$. graminis f. sp. avenae in barley, as previously shown by Dracatos et al. (2014), was polygenically inherited. Several studies on the inheritance of near-nonhost resistance in barley to multiple heterologous rust pathogens using the same mapping populations as the present study also determined that resistance was polygenically inherited, with the rare involvement of an $R$ gene (Jafary et al. 2006; 2008; Niks et al. 2015; Yeo et al. 2014).

Studies on the inheritance of (near-) nonhost resistance when a mono- or oligogenic inheritance was reported (Golegaonkar et al. 2013; Niu et al. 2014; Rodriguez et al. 2004; Sui et al. 2010) were based on classification of progeny according to an infection type scale of 0 to 4 or 0 to 9 . Segregating populations were classified as resistant versus susceptible based on a cutoff in this infection type scale. Frequency distributions were not given, but it is suggested that the distribution was bimodal. We followed a quantitative approach, using a settling tower and counts of flecks and pustules, and did not find discrete infection types but, rather, a quantitative and not bimodal variation in numbers of uredinia and flecks as reported in previous studies (Jafary et al. 2006; 2008; Niks et al. 2015; Yeo et al. 2014) (Fig. 2). Although we suggest that the method of evaluation may play a role in the ability to detect minor effect QTL, the observed differences between studies may also be due to really different modes of inheritance, depending on the plant accession-pathogen isolate combination.

Isolate specificity. Results from recent QTL mapping studies in barley have shown a high diversity of near-nonhost resistance genes to heterologous rust pathogens with different but, also, overlapping specificities (Dracatos et al. 2014; Jafary et al. 2006, 2008). Some QTL were effective to only one tested heterologous rust fungal species and others to several (Jafary et al. 2006, 2008), as again illustrated in Table 4. In previous studies, usually only one isolate per rust species was tested, so there is not much information on possible isolate specificity of QTL for nonhost resistance. The QTL mapping data reported here were based on SP cultures from three genetically diverse Swedish $P$. graminis $\mathrm{f}$. $\mathrm{sp}$. avenae populations that differed in virulence spectrum (Table 1) and occurred in association with barberry (Berlin et al. 2013). The isolates were prone to form telia for sexual reproduction, as evidenced by premature telial formation on barley seedlings, especially by the Ingeberga isolate. Despite the probably great genetic diversity among the isolates, Rpgaql was effective to all isolates and appears to be the same QTL reported by Dracatos et al. (2014), who found it was effective against all $P$. graminis f. sp. avenae isolates tested from Australia and Canada. These results indicate that this resistance gene, in case it plays a role in PAMP-triggered immunity, cannot be suppressed by a corresponding effector in any of the tested isolates of $P$. graminis $\mathrm{f}$. sp. avenae. Rpgaq1 is a QTL with a major effect, accounting for up to $27 \%$ of the phenotypic variation and, presumably, contributes substantially to the immunity observed in both Vada and Golden Promise, although other, minor-effect QTL were also identified. Furthermore, we identified a QTL on chromosome 6H (Rpgaq3) in the Cebada Capa $\times$ SusPtrit and the Vada $\times$ SusPtrit mapping populations effective to two $P$. graminis $\mathrm{f}$. sp. avenae isolates, to $P$. graminis $\mathrm{f}$. $\mathrm{sp}$. lolii, and to $P$. graminis f. sp. tritici. This is similar to the effectiveness of Rpg5 to isolates representing at least three formae speciales of $P$. graminis (Dracatos et al. 2015). Taken together, this suggests that either the same QTL is effective to multiple $P$. graminis formae speciales or the presence of a cluster of tightly linked barley resistance genes that are specific to one or more formae speciales.

In contrast to these apparently nonspecific resistance genes, we also found genes that were clearly $P$. graminis $\mathrm{f}$. sp. avenae isolatespecific. Remarkably, seedlings of SusPtrit were moderately susceptible to the Ingeberga and Pattala isolates but completely resistant (only pinpoint flecking) to Evertsholm. This resistance was mainly due to a resistance allele at the Rpgaq5 locus at the tip of 7HS contributed by SusPtrit, which greatly hampers infection by the Evertsholm isolate, and less so by the Pattala isolate and is ineffective to the Ingeberga isolate. The observed isolate specificity is likely to reflect genetic variation in the allele for the relevant effector within the Swedish $P$. graminis f. sp. avenae populations used in this study.

Barley cultivar and accession-specific resistance. The Rpgaq5 resistance of SusPtrit to isolate Evertsholm was most likely derived from one of the four accessions used for the development of SusPtrit (Menelik, L100, Nigrinudum, and Trigo Biasa). In this study, Menelik, L100, and Nigrinudum were not available. However, Trigo Biasa may be the source of the SusPtrit resistance gene at chromosome $7 \mathrm{H}$, since this line had a similar resistance associated with pinpoint flecks to isolate Evertholm and was moderately susceptible to the Ingeberga isolate. Rpgaql was identified in the present study in both the Vada $\times$ SusPtrit and SusPtrit $\times$ Golden Promise mapping populations and colocated with a previously identified QTL for resistance to $P$. graminis $\mathrm{f}$. sp. avenae in a DH population based on the Australian barley cultivars Yerong and Franklin (Dracatos et al. 2014). Rpgaql likely occurs in several barley 
accessions, including Vada, Yerong, and Golden Promise, but not in Cebada Capa or Franklin. Baker et al. (1970) determined that Srl8 (present in $95 \%$ of common wheats) provided near-nonhost resistance to the heterologous rust pathogen $P$. graminis $\mathrm{f}$. sp. secalis. It is likely that similar genes also play a role in near-nonhost resistance in barley to heterologous rust pathogens. In summary, we identified nine different QTL for resistance in the three barley mapping populations studied. Rpgaql and Rpgaq5 located on chromosomes $1 \mathrm{H}$ and $7 \mathrm{H}$, respectively, are well-suited for mapbased cloning due to their large size effect and the availability of BAC libraries for both Vada and SusPtrit to physically map the responsible regions (Yeo et al. 2016).

\section{ACKNOWLEDGMENTS}

The authors acknowledge A. Vels for technical assistance throughout the duration of the project. The authors thank the Australian Government for funding the project and P. M. Dracatos as an Endeavour Executive Award Fellow and the Grains Research and Development Corporation for financial support.

\section{LITERATURE CITED}

Aghnoum, R., Marcel, T. C., Johrde, A., Pecchioni, N., Schweizer, P., and Niks, R. E. 2010. Basal resistance of barley to barley powdery mildew: Connecting QTLs and candidate genes. Mol. Plant-Microbe Interact. 23:91-102.

Atienza, S. G., Jafary, H., and Niks, R. E. 2004. Accumulation of genes for susceptibility to rust fungi for which barley is nearly a nonhost results in two barley lines with extreme multiple susceptibility. Planta 220:71-79.

Baker, E. P., Sanghi, A. K., McIntosh, R. A., and Luig, N. H. 1970. Cytogenetical studies in wheat III. Studies of a gene conditioning resistance to stem rust strains with unusual genes for avirulence. Aust. J. Biol. Sci. 23:369-375.

Berlin, A., Samils, B., Djurle, A., Wirsen, H., Szabo, L., and Yuen, J. 2013. Disease development and genotypic diversity of Puccinia graminis f. sp. avenae in Swedish oat fields. Plant Pathol. 62:32-40.

Burdon, J. J., Marshall, D. R., and Oates, J. D. 1992. Interaction between wild and cultivated oats in Australia. Pages 82-87 in: Proceeding of the 4th International Oat Conference, Vol. 2. A. R. Barr and R. W. Medd, eds. Adelaide, Australia.

Dracatos, P., Singh, D., Fetch, T., Jnr., and Park, R. F. 2015. Resistance to Puccinia graminis f. sp. avenae in barley is associated with the Rpg 5 Locus. Phytopathology 105:490-494.

Dracatos, P. M., Ayliffe, M., Khatkar, M. S., Fetch, T., Singh, D., and Park, R. F. 2014. Inheritance of prehaustorial resistance to Puccinia graminis f. sp. avenae in barley (Hordeum vulgare L.). Mol. Plant-Microbe Interact. 27:1253-1262.

Golegaonkar, P. G., Wellings, C. R., Singh, D., and Park, R. F. 2013. Genetic and molecular analyses of resistance to a variant of Puccinia striiformis in barley. J. Appl. Genet. 54:1-9.

Heath, M. C. 1985. Implications of nonhost resistance for understanding hostparasite interactions. Pages 25-42 in: Genetic basis of biochemical mechanisms of disease. J. V. Groth, and W. R. Bushnell, eds. APS Press, St. Paul.

Hoogkamp, T. J. H., Chen, W.-Q., and Niks, R. E. 1998. Specificity of prehaustorial resistance to Puccinia hordei and to two inappropriate rust fungi in barley. Phytopathology 88:856-861.

Jafary, H., Albertazzi, G., Marcel, T. C., and Niks, R. E. 2008. High diversity of genes for nonhost resistance of barley to heterologous rust fungi. Genet. 178:2327-2339.

Jafary, H., Szabo, L. J., and Niks, R. E. 2006. Innate nonhost immunity in barley to different heterologous rust fungi is controlled by sets of resistance genes with different and overlapping specificities. Mol. Plant-Microbe Interact. 19:1270-1279.

Jin, Y., Steffenson, B. J., and Miller, J. D. 1994. Inheritance of resistance to pathotypes QCC and MCC of Puccinia graminis f. sp. tritici in barley line Q21861 and temperature effects on the expression of resistance. Phytopathology 84:452-455.

Kochman, J. K., and Brown, J. F. 1975. Development of the stem and crown rust fungi on leaves, sheaths and peduncles of oats. Phytopathology 65: 1404-1408.
Leonard, K. J., and Szabo, L. J. 2005. Stem rust of small grains and grasses caused by Puccinia graminis. Mol. Plant Pathol. 6:99-111.

Mains, E. B. 1933. Host specialization in the leaf rust of grasses, Puccinia rubigo-vera. Paper from the Michigan Academy of Science, Arts, and Letter 17:289-394.

Martens, J. W., Burnett, P. A., and Wright, C. M. 1977. Virulence in Puccinia coronata $\mathrm{f}$. sp. avenae and $P$. graminis $\mathrm{f}$. sp. avenae in New Zealand. Phytopathology 67:1519-1521.

Martens, J. W., Green, G. J., and Buchannon, K. W. 1983. Inheritance of resistance to Puccinia graminis f. sp. avenae in a Hordeum vulgare selection. Can. J. Plant Pathol. 5:266-268.

McDonald, B. A., and Linde, C. 2002. Pathogen population genetics, evolutionary potential, and durable resistance. Annu. Rev. Phytopathol. 40: 349-79.

Mellqvist, E., and Waern, P. 2010. Svampbekämpning i havre. Pages 189-191 in: Försöksrapport 2009 För Mellansvenska Försökssamarbetet och Svensk Raps. A.-K. Krijger, ed. Hush ${ }^{\circ} l$ ningssällskapens Multimedia, Stockholm, Sweden.

Niks, R. E. 1982. Early abortion of colonies of leaf rust, Puccinia hordei, in partially resistant barley seedlings. Can. J. Bot. 60:714-723.

Niks, R. E. 1983. Haustorium formation by Puccinia hordei in leaves of hypersensitive, partially resistant, and nonhost plant genotypes. Phytopathol. 73:64-66.

Niks, R. E. 1986. Variation of mycelial morphology between species and formae speciales of rust fungi of cereals and grasses: Difference in mycelial morphology and spore sizes. Can. J. Bot. 64:2976-2983.

Niks, R. E. 1987. Nonhost plant species as donors for resistance to pathogens with narrow host range. I. Determination of nonhost status. Euphyt. 36: $841-852$

Niks, R. E., Alemu, S. K., Marcel, T. C., and van Heyzen, S. 2015. Mapping genes in barley for resistance to Puccinia coronata from couch grass and to P. striiformis from brome, wheat and barley. Euphyt. 206:487-499.

Niks, R. E., Kerckhoffs, B. M. F. J., and de la Rosa, R. 1996. Susceptibility of cultivated and wild barley (Hordeum vulgare sensu lato) to the leaf rust fungi of wheat and wall barley. Cer. Rust. Powd. Mild. Bull. 24:3-10.

Niks, R. E., and Kuiper, H. J. 1983. Histology of the relation between minor and major genes for resistance of barley to leaf rust. Phytopathol. 73:55-59.

Niks, R. E., and Marcel, T. C. 2009. Nonhost resistance and basal resistance: How to explain specificity? New Phytol. 182:817-828.

Niks, R. E., Parlevliet, J. E., Lindhout, P., and Bai, Y. 2011. Breeding Crops with Resistance to Diseases and Pests. Wageningen Academic Publishers, Wageningen, The Netherlands.

Niks, R. E., and Rubiales, D. 2002. Potentially durable resistance mechanisms in plants to specialised fungal pathogens. Euphyt. 124:201-216.

Niu, Z., Puri, K. D., Chao, S., Jin, Y., Sun, Y., Steffenson, B. J., Maan, S. S., Xu, S. S., and Zhong, S. 2014. Genetic analysis and molecular mapping of crown rust resistance in common wheat. Theor. Appl. Genet. 127:609-619.

Qi, X., Niks, R. E., Stam, P., and Lindhout, P. 1998. Identification of QTLs for partial resistance to leaf rust (Puccinia hordei) in barley. Theor. Appl. Genet. 96:1205-1215.

Rodriguez, P., Garrood, J. M., Shen, Q. H., Smith, P. H., and Boyd, L. A. 2004. The genetics of nonhost disease resistance in wheat to barley yellow rust. Theor. Appl. Genet. 109:425-432.

Sui, X., He, Z., Lu, Y., Wang, Z., and Xia, X. 2010. Molecular mapping of a non-host resistance gene YrpstY1 in barley (Hordeum vulgare L.) for resistance to wheat stripe rust. Hereditas 147:176-182.

Sun, Y., Steffenson, B. J., and Jin, Y. 1996. Genetics of resistance to Puccinia graminis f. sp. secalis in barley line Q21861. Phytopathol. 86: 1299-1302.

Van Ooijen, J. W. 2009. MapQTL6, software for the mapping of quantitative trait loci in experimental populations of diploid species. Kyazma B.V., Wageningen, Netherlands.

Yeo, F. K. S., Hensel, G., Vozábová, T., Martin-Sanz, A., Marcel, T. C., Kumlehn, J., and Niks, R. E. 2014. Golden SusPtrit: A genetically well transformable barley line for studies on the resistance to rust fungi. Theor. Appl. Genet. 127:325-337.

Yeo, F. K. S., Wang, Y., Vozabova, T., Huneau, C., Leroy, P., Chalhoub, B., Qi, X. Q., Niks, R. E., and Marcel, T. C. 2016. Haplotype divergence and multiple candidate genes at Rphq2, a partial resistance QTL of barley to Puccinia hordei. Theor. Appl. Genet. 129:289-304. 